\title{
The Impact of Central Bank of Liberia Guidelines on Inbound Money Transfers in Liberia (The Liberian Bank for Development and Investment 2016-2018)
}

\author{
Jerome M. Kesselly \\ Master of Business Management, Texila American University, Liberia
}

\begin{abstract}
The Central Bank of Liberia (CBL), according to its mandate under the Act of 1999 and its authority, in line with Section 55 and 39, on November 15, 2016, issue a regulation (No. CBL/RSD/004/2016) on payment of Inbound money transfers, which was ordered by former President of the Republic of Liberia, Madam Ellen Johnson Sirleaf, and the Minister of Foreign Affairs. The objective of this regulation was to support the effective management of the foreign exchange market. The regulation applies to all licensed financial institutions involved in money transfer services, such as Western Union and MoneyGram. The regulation did not apply to inbound money transfers that are made using recipient accounts at commercial banks. Conclusion: The theoretical framework presented in this research suggests that commercial banks, be precise, the Liberia Bank for Development and Investment (LBDI), are more likely to suffer a decrease in commission on inbound money transfers throughout the three years (3) of restrictions.
\end{abstract}

Keywords: Commercial Bank, Currencies Transactions, Impact, Regulations, Transfers.

\section{Introduction}

The Central Bank of Liberia (CBL) issued a new regulation on inbound money transfer through a press release by the Communication Director, Cyrus Wleh Badio [1]. The release, a copy which in the position of the [2] states that individuals receiving remittance from abroad will receive 25\% payments in Liberian Dollars and $75 \%$ in United States Dollars.

The regulation comes in the wake of the [3], which indicates that the Liberian Government was facing foreign exchange problems based on the drop in iron ore, and rubber price on the world market. The regulation took effect on December 1, 2016. This research details the plan on 'the Impact of Central Bank of Liberia Guidelines on Inbound Money Transfers in Liberia (The Liberian Bank for Development \& Investment 2016-2018) as a case study.

This research describes the problem, research questions, and method overview, which also explain the research design approach, population, and ethical considerations. The final part of this research contains a result and conclusion sections [4].

\section{Research Questions}

1. What impact do the guidelines on inbound money transfers have on the Liberian economy?

2. What are the factors that lead to the issuing of the inbound money transfers guidelines in Liberia?

3. What impact did this guideline had on commercial banks? To be precise, the Liberia Bank for Development in Investment (LBDI).

4. What were the outcomes of the guidelines in the three years of implementation? To be precise, the Liberia Bank for Development and Investment (LBDI). 
5. What effect the exchange rate had on the inbound money transfer guidelines within the three years of implementation?

\section{Literature Review and Method}

This chapter of the research provides a detailed perspective of the research topic. The review of literature focused on The Impact of Central Bank of Liberia Guidelines on Inbound Money Transfers in Liberia (The Liberian Bank for Development \& Investment 2016-2018) as a case study. Inbound money transfer services are theorized to strengthen growth through several channels in banks, including facilitating entrepreneurial investments, insurance against unexpected shocks, smoothing household consumption patterns, financing household savings, etc.

On the other hand, inbound money transfer services can put up growth impeding effects if households substitute transfers receipts for labor income, thus, adversely affect labor supply and reduces the number of productive hours available to the economy [5]. In such a situation, remittance-receiving households replace productive labor hours with leisure hours.

\section{Inbound Money Transfer Service at the LBDI}

Inbound money remittance Services at the Liberia Bank for Development and Investment are MoneyGram and Western Union.

Moneygram-is a money transfer company based in the United States with headquarters in Dallas, Texas. The bank uses this service to raise income, pay its staff, and buzz the economy.

Western Union- is an American worldwide financial service and communications company. It headquarters is in Denver, Colorado. In terms of value and volume, Western Union and MoneyGram are the main services used for person-to-person transfer. These services do not require a bank account. They allow cash to be collected. Surprisingly, these services are primarily used for international transfers.

\section{Incoming Money Gram and Western Union Transfer Operations}

For incoming transfer operations at LBDI, walk-in customers make entry into any of the bank outlets with a valid identification card (ID), he/she is served by any customer service officer assign at the bank to fill in their transfer information. The form is presented to a teller to pass the required entries, and cash is disbursed to the customer.

\section{The Currency of Payment on Inbound Transfers}

CBL Regulation No. CBL/RSD/004/2016 concerning payment of Inbound Money Transfers, the Central Bank of CBL mandated all commercial banks operating in the country to pay their customers Twenty-five percent $(25 \%)$ in Liberian Dollars; and Seventy-five percent (75\%) in United States Dollars accordingly [6].

\section{Exchange Rate}

An increase in Inbound money transfer allows the bank to intervene in the foreign exchange market for the clear purpose of maintaining stability [7]. The commercial banks were mandated to use CBL published selling rate on the date of the payment. The exchange rate was conspicuously displayed on the premises of all commercial banks.

\section{Commission/Revenue on Inbound Money Transfer}

Commissions on inbound money transfers are revenue generated from the inbound transfer. Ten percent $(10 \%)$ on both inbound outbound transactions is recognized as marketing expenses, payable at the point of normalization, and deducted from an aggregate commission by the agent of western union or MoneyGram. The $10 \%$ is subsequently reversed to the commission account when the actual marketing activity is executed. Table 1 variance analysis on commissions that were generated from 2016 to 2017, and from 2017 to 2018 . 
Table 1. CBL Prevailing Exchange Rate from 2016-2018

\begin{tabular}{|l|l|l|l|}
\hline Month & Rate use in 2016 & Rate use in 2017 & Rate use in 2018 \\
\hline January & 84.66 & 93.00 & 128.78 \\
\hline February & 84.66 & 91.37 & 130.10 \\
\hline March & 84.66 & 92.00 & 131.75 \\
\hline April & 84.66 & 91.47 & 132.59 \\
\hline May & 84.67 & 92.00 & 137.79 \\
\hline June & 84.67 & 92.00 & 149.23 \\
\hline July & 84.67 & 113.51 & 160.79 \\
\hline August & 94.94 & 114.68 & 150.60 \\
\hline September & 91.00 & 117.10 & 155.34 \\
\hline October & 91.00 & 118.93 & 156.69 \\
\hline November & 91.00 & 125.17 & 157.49 \\
\hline December & 98.00 & 125.20 & 157.61 \\
\hline
\end{tabular}

Source: LBDI MoneyGram and Western Union Department management

\section{Methodology of Study}

This research gives a brief explanation of the research design. A research design is a general plan of how the researcher goes about answering the research questions [8]. According to [9], this study adopted a descriptive research design. [10] suggested descriptive, if the research aim is to identify characteristics, frequencies, trends, and categories. This research aims to collect data on the frequencies of inbound money transfers in Liberia.

\section{Collection of Data}

Data collection is a process of gathering and measuring information on targeted variables in an established systematic fashion, which enables answers to relevant questions and evaluates the outcomes [11]. Data was collected using a quantitative survey questionnaire containing structure questions.

The researcher adopted open-ended questions for this research, with the aim of getting information that lessens information bias and makes it easy for the data analysis. Employ structure interview guide to all the objectives and selected respondents. The researcher makes sure that the research supervisor reviewed and validated the instruments to ensure the instruments covered all possible aspects. The researcher pre-tested the instruments before they were used in the field.

\section{Data Analysis}

The researcher analyzed data using a quantitative approach, using a survey questionnaire containing structured questions. The result of the Analysis was documented in tables that were used to Analyzed all data from evaluating respondents.

\section{The Results of the Research}

This research presents the results of quantitative data analysis and relation to previous studies. It provides an in-depth understanding of the research. Every year, there was an increase in average exchange rates (eg. In 2016); the average exchange rate increase from 98LD/1USD to $125.20 \mathrm{LD} / 1 \mathrm{USD}$, which is a $27.55 \%$ increase in the average rate at the end of 2017. The rate also increases from 2017 to 2018 , which is $28.43 \%$ (see Table 2).

After conducting the Average Rate Analysis in (Table 2), the researcher selected twenty transactions from each year to analyze the percentage of Liberian dollars to United States dollars, applying the average rate. See Table-3.

Base on the analysis, the researcher observed more Liberian dollars' circulation in the economy than United states dollars that led to an 
increase in the exchange rate and a decrease in commission on inbound money transfer. See Table 4.

MoneyGram and Western Union services are profit-driven services of banks, but due to Inbound Money Transfer Regulation issued by CBL in 2016 led to flotation in commission from 2016 to 2018. See Table- 4. Variance analysis on commission was conducted from 2016 to 2018 .
Operational results on commission from Inbound Money Transfer from 2016 to 2017 decreased by $-1 \%$ or US $\$-4,445.00$, which led to a decrease between 2017 and 2018 by $-8 \%$ or US\$-51,324.00.

The Regulation mandated to split every Inbound money transfer, 25\% Liberia dollars and $75 \%$ United States dollars. See Table-3 Analysis.

Table 2. Average Exchange Rate

\begin{tabular}{|l|l|l|}
\hline Year & Maximum Rate use & Minimum Rate use \\
\hline 2016 & 98.00 & 84.66 \\
\hline 2017 & 125.20 & 90.00 \\
\hline 2018 & 160.79 & 120.30 \\
\hline
\end{tabular}

Table 3. Average Exchange Rate Analysis of $25 \%$ LD in each Fiscal year of the Bank operations

\begin{tabular}{|c|c|c|c|c|c|c|}
\hline Year & $\begin{array}{l}\text { Amount of } \\
\text { transactions }\end{array}$ & $\begin{array}{l}\text { Total Amount of } \\
\text { Inbound in USD }\end{array}$ & $\begin{array}{l}75 \% \text { in } \\
\text { USD }\end{array}$ & $\begin{array}{l}\text { Average } \\
\text { Rate }\end{array}$ & $25 \%$ USD & $\begin{array}{l}25 \% \text { equivalent in } \\
\text { LD at average Rate }\end{array}$ \\
\hline 2016 & 25 & $10,340.00$ & $7,755.00$ & 91.33 & $2,585.00$ & $236,088.05$ \\
\hline 2017 & 25 & $15,480.00$ & $11,610.00$ & 107.60 & $3,870.00$ & $416,412.00$ \\
\hline 2018 & 25 & 8.650 .00 & $6,487.50$ & 140.545 & $2,162.50$ & $303,928.56$ \\
\hline Total & 75 & $34,470.00$ & $25,852.50$ & 110.99 & $8,617.50$ & $956,428.61$ \\
\hline
\end{tabular}

Table 4. Variance Analysis on Commission from 2016 to 2018

\begin{tabular}{|l|l|l|l|}
\hline In united stated Dollars & 31-Dec-16 & 31-Dec-17 & Variance \\
\hline Commission on MoneyGram operations & 499,909 & 430,212 & $-69,697$ \\
\hline Commission on western union operations & 162,425 & 227,677 & 65,252 \\
\hline Total & 662,334 & 657,889 & $-4,445$ \\
\hline In united stated Dollars & $31-$ Dec-17 & $31-$ Dec-18 & Variance \\
\hline Commission on MoneyGram operations & 430,212 & 420,952 & $-9,260$ \\
\hline Commission on western union operations & 227,677 & 185,613 & $-42,064$ \\
\hline Total & 657,889 & 606,565 & $-51,324$ \\
\hline
\end{tabular}

Source: Audited Bank Financial Statements

\section{Discussion}

In previous sections, outcomes were presented. In this section, they are summarized and compared to the literature review. The most significant and surprising outcome is the negative impact for insurance of the new regulation on Inbound Money Transfer in Liberia.

Base on the flotation of the exchange rate, LBDI did not benefit, instilled, they had a decrease of $-8 \%$ representing $-51,324.00$ United
States. This amount supersedes commission made by LBDI between 2016, and 2017.

\section{Limitation}

This review was limited due to time and resources, where the author could not meet the MoneyGram \& Western Union Department manager in person for detailed pieces of information about their services but had to use phone calls for communication. 


\section{Conclusions}

Since the survey outcomes did completely fit the literature review, the research questions were answered explicitly. The theoretical framework presented in this research suggests that commercial banks, be precise the Liberia Bank for Development and Investment (LBDI), likely suffer a decrease in commission on inbound money transfers. However, the survey results did partially confirm this point of view.

\section{Recommendations}

This research suggests strategies from the Central Bank of Liberia in stabilizing the exchange rate to keep commercial banks in business and maintain their agent status with the Inbound money transfer companies.

Additionally, there is a need to collaborate with the Central Bank of Liberia in implementing the regulation to avoid penalties and add value to commercial banks in the country.

\section{Reference}

[1] The Central Bank of Liberia (2016). Gazette Published by Authority/ Regulation on payment of inbound money transfer (2016. N0.83). Retrieved From: https://www.cbl.org.lr/doc/inbound.pdf.

[2] African Star (2016). Article. Liberia Places Restrictions on Money Transfers Retrieved From: https://www.africanstar.org.

[3] The Central Bank of Liberia (2016-2019). Annual Reports. Retrieved From:

https://www.yumpu.com/en/document/view/570605 50/january-1-2016-to-december- 31-2016.

[4] K.J Sileyeh (2019) Research designed methodology Retrieved from: https://www.intechopen.com/chapters/68505.

[5] Chami et al (2005). Immigrant Remittance Retrieved From:

https://www.researchgate.net/publication/5124172_

Are_Immigrant_Remittance_Flow_a_Source_Capita 1_for_Development

[6] Ministry of Foreign Affairs Article (2016). InBound Money Transfers to Be Paid in Dual

\section{Conflicts of Interest Statement}

This paper Title: The Impact of Central Bank of Liberia Guidelines on Inbound Money Transfers in Liberia (the Liberian Bank for Development \& Investment 2016-2018).

The author, whose name is mentioned immediately below, certified that he has NO affiliation with or involvement in any institution with a financial interest, such as honoraria; educational grant; employment; or non-financial interest such as personal or professional relationship, affiliations in the subject matter, or materials discussed in this paper.

\section{Acknowledgment}

The Author of this research would like to take this time to thank the Almighty for giving him the strength and knowledge in doing this work. And also, the management and staff of the Liberian Bank for Development \& Investment (LBDI) in helping with all the necessary pieces of information for the success of this work.

Currency/SWIFT/Transfers/Exempt. Retrieved From:

https://www.mofa.gov.lr/public2/2press.php?news_i $\mathrm{d}=2352 \&$ related $=7 \& \mathrm{pg}=$ sp.

[7] Free currency rates (2016). Online Currency Converter Retrieved From:

https://freecurrencyrates.com/en/exchange-ratehistory/USD-LRD/2016_20.

[8] Creswell, J. W. (2003). Research design: Qualitative, quantitative, and mixed methods approach (2nd ed.). Thousand Oaks, CA: Sage.

[9] Mouton (2001, p. 55) Research design Retrieved from: https://silo.tips/download/chapter-3-researchmethodology.

[10] Shona McCombes (2019). Suggestion on descriptive research design. Retrieved From: https://www.scribbr.com/methodology/descriptiveresearch/.

[11]DeMarrais (2004). Study methods and Data Collection Retrieved from: https://www.researchgate.net/publication/291456164 _Qualitative_interview_studies_Learning_through_e xperience. 